\title{
FATORES DE RISCO E SINTOMATOLOGIA CLÍNICA ASSOCIADOS À INFECÇÃO PELO FELV: ESTUDO CASO-CONTROLE EM UM HOSPITAL ESCOLA VETERINÁRIO
}

\author{
RISK FACTORS AND CLINICAL SYMPTOMATOLOGY RELATED WITH \\ FELV: CASE-CONTROL STUDY IN A VETERINARY TEACHING HOSPITAL
}

\author{
Gustavo Carvalho Cobucci ${ }^{*}$ ORCID - http://orcid.org/0000-0002-0997-5221 \\ Evandro Silva Favarato² ORCID - http://orcid.org/0000-0003-2089-864X \\ Paula Dias Bevilacqua² ORCID - http://orcid.org/0000-0003-0015-2154 \\ Bruno Santiago² ORCID - http://orcid.org/0000-0002-4445-5555
}

${ }^{1}$ Faculdade de Ciências e Tecnologia de Viçosa, Viçosa, MG, Brasil

2Universidade Federal de Viçosa, Viçosa, MG Brasil

*Autor para correspondência - gucobucci@hotmail.com

\section{Resumo}

O objetivo do estudo foi identificar fatores de risco e características clínicas da infecção pelo vírus da leucemia felina (FeLV) em gatos domésticos (Felis catus) atendidos em um hospital escola veterinário. Para a determinação dos fatores de risco, foi realizado estudo caso-controle e para a caracterização da sintomatologia clínica dos animais doentes, foi realizado estudo descritivo. Foram avaliados 175 prontuários médicos de gatos atendidos no hospital durante o período de janeiro de 2013 a janeiro de 2014, sendo 34 animais $(19,4 \%)$ positivos para o vírus. Foi observada associação entre idade e infecção pelo FeLV ( $\mathrm{p}=0,009)$, em que a maior incidência da infecção ocorreu em animais com idade entre um e quatro anos. Neoplasias hematopoiéticas $(p=0.00002)$, anemia $(p<0,0000001)$, leucopenia $(\mathrm{p}=0,04)$ e hiperproteinemia $(\mathrm{p}=0,043)$ estiveram associadas com a FeLV. Sinais clínicos associados aos sistemas respiratório, digestório, tegumentar e nervoso estiveram presentes em $20,6 \%, 14,7 \%$, $5,9 \%$ e $5,9 \%$, respectivamente. Concluiu-se que a idade está associada à infecção pelo FeLV, sendo o grupo de animais entre um e quatro anos com maior risco, enquanto sexo e acesso à rua não são fatores de risco para a infecção. A infecção pelo FeLV está associada à anemia, leucopenia, neoplasias hematopoiéticas e hiperproteinemia.

Palavras-chave: Doenças infecciosas, epidemiologia, Leucemia viral felina, retrovírus.

\begin{abstract}
The objective of this study was to identify risk factors and clinical features of the feline leukemia virus (FeLV) infection in domestic cats (Felis catus) seen at a Veterinary Teaching Hospital. A casecontrol study was performed to determine the risk factors and a descriptive study was done to define the clinical symptoms of the sick animals. From January 2013 to January 2014, 175 medical records of cats seen at the hospital were evaluated. FeLV was found in 34 of them (19.4\%). It was noticed an association between age and the FeLV infection ( $p=0,009)$; higher incidence of the infection occurring in animals between one and four years old. Hematopoietic neoplasias $(p=0,000022)$, anemia $(p<0,0000001)$, leukopenia $(p=0,04)$ and hyperproteinemia $(p=0,043)$ were associated with FeLV infection. Unspecific symptoms were observed in $51.8 \%$ of the animals. Clinical signs associated
\end{abstract}


with respiratory, digestive, tegumentary and nervous systems were present in $20.6 \%, 14.7 \%, 5.9 \%$ and $5.9 \%$ respectively. This study concluded that age between one and four years old is a risk factor for FeLV infection. On the other hand, sex and outdoor access are not risk factors for the infection. FeLV infection is associated with anemia, leucopenia, hematopoietic neoplasia and hyperproteinemia.

Keywords: Epidemiology, Feline leukemia virus, infectious diseases, retrovirus.

Recebido em: 20 de dezembro de 2017.

Aceito em 25 de junho de 2019.

\section{Introdução}

A prevalência da infecção pelo vírus da leucemia felina (FeLV) varia de 1,4\% a 15,6\% em gatos clinicamente saudáveis e entre 7,6\% a 30,4\% em gatos doentes ${ }^{(1-5)}$. No Brasil, a análise de amostras de diferentes regiões mostrou grande variação na ocorrência de animais positivos $(0,0 \% \text { a } 34,9 \%)^{(6)}$. Estudos baseados na detecção do antígeno p27 do FeLV ou em métodos de imunofluorescência mostraram prevalência de $6,2 \%^{(7)}$ na cidade de São Paulo, $11,52 \%^{(8)}$ e $18,5 \%{ }^{(9)}$ no Rio de Janeiro e $32,5 \%^{(10)}$ em Belo Horizonte. Entretanto, estudos que utilizaram métodos de detecção de DNA pró-viral demonstraram uma prevalência maior de infecção $(47,5 \%)$ em relação a esses estudos ${ }^{(11)}$. Estudos anteriores identificaram idade, sexo, estado reprodutivo, acesso à rua, tipo de habitação e coabitação com múltiplos gatos como fatores de risco para a infecção pelo $\mathrm{FeLV}^{(5,6,8,12)}$.

Animais FeLV positivos apresentam ampla variedade de sinais clínicos. As consequências mais comuns da infecção são imunossupressão, anemia, desordens mieloproliferativas, linfoma, leucemia e outras síndromes, incluindo neuropatias, dermatopatias, enteropatias e desordens reprodutivas ${ }^{(13-15)}$. Em gatos, conseguiu-se estabelecer associação entre animais infectados pelo vírus e o desenvolvimento de linfomas ${ }^{(16)}$. Sabe-se que felinos FeLV positivos apresentam 62 vezes mais predisposição para desenvolver linfoma ou leucemia que gatos não infectados ${ }^{(15)}$.

O objetivo geral desse estudo foi identificar fatores de risco e características clínicas da infecção pelo FeLV em gatos domésticos (Felis catus) atendidos em um hospital escola veterinário localizado no estado de Minas Gerais, Brasil, no período de janeiro de 2013 a janeiro de 2014. Os objetivos específicos foram analisar a existência de associação entre idade, sexo, acesso à rua e estado reprodutivo e infecção pelo FeLV; bem como analisar os principais achados clínicos e laboratoriais dos animais infectados.

\section{Material e métodos}

A pesquisa envolveu dois delineamentos. Para a determinação dos fatores de risco, foi realizado estudo caso-controle e para a caracterização da sintomatologia clínica dos animais doentes, foi realizado estudo descritivo. No estudo caso-controle, foram selecionados todos felinos atendidos na rotina de um hospital veterinário (HOV) do estado de Minas Gerais, Brasil, durante os meses de janeiro de 2013 a janeiro de 2014. Os animais selecionados compuseram os grupos de casos e controles e cumpriram os seguintes critérios definidores: grupo caso - composto por felinos domésticos (Felis catus) atendidos no HOV, com prontuário apresentando informações sobre aspectos biológicos, clínicos e hábitos comportamentais do animal e com resultado positivo para a pesquisa do antígeno p27 do FeLV; e 
grupo controle - constituído por felinos domésticos atendidos no HOV, com prontuário apresentando informações sobre aspectos biológicos, clínicos e hábitos comportamentais do animal e com resultado negativo para a pesquisa do antígeno p27.

A amostra do estudo se caracterizou como amostra de conveniência, sendo constituída por todos os animais atendidos no HOV de janeiro de 2013 a janeiro de 2014 que preencheram os critérios de caso e controle descritos acima. Os animais foram testados para a presença do FeLV utilizando-se o teste FIV Ac/FeLV Ag Test Kit (FIV Ac/FeLV Ag Test Kit - Alere S.A. Pinheiros, São Paulo, Brasil), um imunoensaio cromatográfico utilizado para detecção qualitativa do antígeno p27 do FeLV em sangue total. A sensibilidade e especificidade do teste utilizado foi de $100 \%$, de acordo com as informações do fabricante; e de 90,7 e 97,8\%, respectivamente, de acordo com Medeiros et al. ${ }^{(9)}$.

Para o estudo dos fatores de risco, os prontuários clínicos dos animais foram consultados para obtenção de dados referentes às variáveis biológicas, hábitos comportamentais e clínicos. As variáveis biológicas coletadas e suas respectivas categorias foram: idade (menor de um ano, entre um e quatro anos e maior de quatro anos), sexo (macho/fêmea) e estado reprodutivo (esterilizado/não esterilizado). Optou-se por dividir os animais nas faixas etárias acima mencionadas, de forma semelhante a outros estudos epidemiológicos realizados no Brasil ${ }^{(7,8)}$. A variável analisada relacionada aos hábitos comportamentais foi o acesso à rua (sim/não). Com relação aos dados clínicos, foram analisadas as variáveis hematológicas: anemia (hematócrito $<24 \%$ ), não-anemia (hematócrito $>24 \%$ ), leucocitose (leucócitos $>19.500$ células $/ \mathrm{mm}^{3}$ ), leucopenia (leucócitos $<5.500$ células $/ \mathrm{mm}^{3}$ ), hiperproteinemia (proteína plasmática total $>8 \mathrm{~g} / \mathrm{dL}$ ), hipoproteinemia (proteína plasmática total $<6 \mathrm{~g} / \mathrm{dL}$ ), azotemia (ureia $>60 \mathrm{mg} / \mathrm{dL}$, creatinina $>1,8 \mathrm{mg} / \mathrm{dL}$ ) e aumento de enzimas hepáticas [Alanina aminotransferase $($ ALT $)>90 \mathrm{UI} / \mathrm{L}$, Aspartato aminotransferase $($ AST $)>80 \mathrm{mg} / \mathrm{dL}$ e Fosfatase alcalina (FA) $>288 \mathrm{UI} / \mathrm{L}]$ e a variável neoplasia hematopoiética [presença ou ausência de neoplasia hematopoiética (linfoma ou leucemia)].

Para a análise descritiva da sintomatologia clínica dos animais doentes, foram coletados dados dos prontuários clínicos relacionados à presença de: sintomas (sintomático ou assintomático), sintomas inespecíficos (apatia, hiporexia, emaciação, linfadenomegalia) e sistemas acometidos (respiratório, gastrointestinal, neurológico, dermatológico). Considerando o delineamento caso-controle, inicialmente os dados referentes às variáveis biológicas, hábitos comportamentais e clínicos dos animais e o resultado da pesquisa do antígeno p27 do FeLV foram sistematizados em tabelas de frequência considerando as respectivas categorias e os grupos caso e controle.

As análises de associação entre as variáveis explicativas (biológicas, hábitos comportamentais e clínicos) e o desfecho (resultado da pesquisa do antígeno p27 do FeLV) foram realizadas por meio da construção de tabelas de contingência e cálculo do Chi-quadrado e a intensidade de associação foi determinada pelo cálculo da razão de chances. As interpretações das análises foram feitas considerando o nível de significância de 5\%. As análises estatísticas foram realizadas no Programa EpiInfo $^{\text {TM }}$ versão 7.1.2. As análises descritivas foram apresentadas em forma de texto. Essa pesquisa foi submetida à Comissão de Ética no Uso de Animais da Instituição de Ensino, tendo o Parecer aprovado conforme processo 90/2013.

\section{Resultados}

Foram avaliados 175 prontuários médicos de felinos atendidos no HOV durante o período de estudo. Trinta e quatro animais $(19,4 \%)$ foram positivos para pesquisa do antígeno p27 do FeLV e, desse 
modo, incluídos no grupo caso. Os demais 141 animais $(80,6 \%)$ foram negativos para a pesquisa de antígeno p27, tendo sido incluídos no grupo controle. Alguns prontuários não apresentavam informações completas sobre as variáveis analisadas. Por isso, em alguns casos o número total das amostras estudadas é inferior ao número total de animais presentes no grupo caso ou controle.

Foi identificada associação estatisticamente significante entre a infecção por FeLV e as variáveis: estado reprodutivo $(\mathrm{p}=0,01)$, idade $(\mathrm{p}=0,01)$, anemia $(\mathrm{p}<0,01)$, alterações leucocitárias $(\mathrm{p}=0,04)$, neoplasias hematopoiéticas $(p<0,01)$ e alterações de proteína total $(p=0,04)($ Tab. 1). Animais com anemia, leucopenia, presença de neoplasias hematopoiéticas e hiperproteinemia apresentaram maiores chance de infecção por FeLV, sendo, respectivamente, 12,39 (IC95\%=4,33-38,91); 3,66 (IC95\%=1,02-13,2); indefinido (IC95\%=12,35-indefinido) e 2,58 (IC95\%=1,09-5,97).

Tabela 1. Distribuição de casos e controles segundo as variáveis explicativas.

\begin{tabular}{|c|c|c|c|c|}
\hline Variáveis & Casos & Controles & Valor de $\mathrm{p}$ & Razão de chances (IC95\%) \\
\hline \multicolumn{5}{|l|}{ Estado reprodutivo } \\
\hline Inteiro & 18 & 99 & \multirow[t]{2}{*}{$0,01^{*}$} & \\
\hline Castrado & 13 & 26 & & $0,37(0,16-0,86)$ \\
\hline \multicolumn{5}{|l|}{ Acesso à rua } \\
\hline Sim & 23 & 83 & \multirow[t]{2}{*}{0,37} & \\
\hline Não & 11 & 46 & & $1,16(0,52-2,67)$ \\
\hline \multicolumn{5}{|l|}{ Idade } \\
\hline$<1$ ano & 8 & 60 & \multirow{3}{*}{$0,01^{*}$} & 1,00 \\
\hline 1 a 4 anos & 17 & 31 & & $0,25(0,09-0,63)$ \\
\hline$>4$ anos & 9 & 27 & & $0,40(0,14-1,19)$ \\
\hline \multicolumn{5}{|l|}{ Sexo } \\
\hline Macho & 21 & 65 & \multirow[t]{2}{*}{0,11} & \\
\hline Fêmea & 13 & 65 & & $1,61(0,74-3,57)$ \\
\hline \multicolumn{5}{|l|}{ Anemia } \\
\hline $\operatorname{Sim}$ & 14 & 6 & \multirow[t]{2}{*}{$<0,01^{*}$} & \\
\hline Não & 20 & 109 & & $12,39(4,33-38,91)$ \\
\hline \multicolumn{5}{|l|}{ Alterações leucocitárias } \\
\hline Leucocitose & 6 & 32 & \multirow{3}{*}{$0,04^{*}$} & $0,70(0,24-1,85)$ \\
\hline Leucopenia & 6 & 6 & & $3,66(1,02-13,2)$ \\
\hline Sem alterações & 21 & 78 & & 1,00 \\
\hline \multicolumn{5}{|c|}{ Neoplasias hematopoiéticas } \\
\hline Sim & 10 & 0 & \multirow[t]{2}{*}{$<0,01^{*}$} & \\
\hline Não & 0 & 8 & & Indf. (12,35-indf.) \\
\hline \multicolumn{5}{|l|}{ Alterações renais } \\
\hline Azotemia & 3 & 5 & \multirow[t]{2}{*}{0,08} & \\
\hline Sem alterações & 12 & 67 & & $3,29(0,58-16,22)$ \\
\hline \multicolumn{5}{|l|}{ Alterações renais } \\
\hline Ureia & 21 & 67 & \multirow{3}{*}{0,08} & $1,74(0,80-3,9)$ \\
\hline Creatinina & 4 & 5 & & $4,36(0,92-19,75$ \\
\hline Sem alterações & 12 & 67 & & 1,00 \\
\hline \multicolumn{5}{|l|}{ Alterações hepáticas } \\
\hline ALT & 7 & 17 & \multirow{4}{*}{0,75} & $1,61(0,53-4,65)$ \\
\hline AST & 11 & 38 & & $1,14(0,45-2,80)$ \\
\hline FA & 15 & 64 & & $0,92(0,40-2,11)$ \\
\hline Sem alterações & 14 & 55 & & 1,00 \\
\hline \multicolumn{5}{|l|}{ Alterações hepáticas } \\
\hline $\operatorname{Sim}$ & 16 & 78 & \multirow[t]{2}{*}{0,30} & \\
\hline Não & 14 & 55 & & $0,81(0,36-1,82)$ \\
\hline \multicolumn{5}{|l|}{ Alterações de proteinas } \\
\hline Hiperproteinemia & 12 & 24 & \multirow{3}{*}{$0,04^{*}$} & $2,58(1,09-5,97)$ \\
\hline Hipoproteinemia & 1 & 1 & & $5,09(0,13-204,0)$ \\
\hline Sem alterações & 21 & 109 & & 1,00 \\
\hline
\end{tabular}


Animais não esterilizados e mais jovens ( $<1$ ano) apresentaram menores chances $(0,37$; IC $95 \%=0,16$ 0,86 e 0,25 ; IC95\%=0,09-0,63, respectivamente) de infecção por FeLV quando comparados aos animais esterilizados e aos com idade entre 1 e 4 anos, respectivamente. Dito de outra forma, animais esterilizados e com idade entre 1 e 4 anos apresentaram maiores chances de infecção por FeLV (2,73; IC95\%=1,17-6,34 e 4,06; IC95\%=1,59-10,99, respectivamente) (Tab. 1).

Dentre os animais positivos para FeLV, 27 apresentavam-se sintomáticos (79,4\%), enquanto sete animais $(20,6 \%)$ apresentavam-se assintomáticos. Sinais inespecíficos como apatia e hiporexia foram encontrados em quatorze $(41,2 \%)$ e doze animais $(35,3 \%)$, respectivamente. Emaciação ocorreu em oito pacientes $(23,5 \%)$ e linfadenomegalia periférica em quatro animais $(11,8 \%)$. Sinais clínicos associados ao sistema respiratório estiveram presentes em sete animais (20,6\%), sendo que seis apresentaram taquipneia, dispneia, esforço inspiratório e respiração abdominal e um animal apresentou secreção purulenta nasal e ocular. Alterações clínicas relacionadas ao sistema gastrointestinal estiveram presentes em cinco animais (14,7\%), sendo que dois apresentaram diarreia, dois hepatomegalia e apenas um apresentou gengivite, halitose, sialorreia e disfagia. Dois animais $(5,9 \%)$ apresentaram lesões dermatológicas e outros dois pacientes $(5,9 \%)$ apresentaram sinais clínicos associados ao sistema nervoso central. Neoplasia hematopoética foi diagnosticada em dez animais FeLV positivos $(29,4 \%)$. Oito deles apresentavam linfoma mediastinal, um apresentava linfoma intestinal e um leucemia linfoblástica aguda. Anemia não regenerativa foi encontrada em $13(38,2 \%)$ gatos positivos e anemia regenerativa em um animal (2,9\%). Este animal também apresentava-se coinfectado com Mycoplasma haemofelis.

\section{Discussão}

O percentual de animais positivos para o FeLV (19,4\%) encontrado no presente estudo foi maior do que o encontrado em estudos epidemiológicos realizados no Rio de Janeiro, $11,5 \%{ }^{(8)}$ e São Paulo, $6,2 \%{ }^{(7)}$. É importante considerar que, diferentemente desses estudos, nossa amostra foi composta por animais atendidos em um hospital veterinário e por isso, subentende-se tratar de indivíduos apresentando algum tipo de doença clínica. Esse fato pode ter contribuído para elevar o percentual de animais positivos para o FeLV, visto que a incidência da doença é maior em animais enfermos do que em animais sadios ${ }^{(3,17,18)}$. No entanto, nosso resultado foi semelhante ao encontrado por Medeiros et al. ${ }^{(9)}(18,5 \%)$ que também utilizaram amostras de animais atendidos em instalações veterinárias.

O teste utilizado no presente estudo permite a detecção da antigenemia do p27 do FeLV, mas não é capaz de identificar a presença de DNA pró-viral em animais que desenvolveram a infecção regressiva ${ }^{(19)}$. Nas infecções regressivas, não há produção ativa de proteínas virais e testes que detectam antígenos virais têm resultados negativos ${ }^{(15)}$. Testes mais sensíveis, como a Reação em Cadeia da Polimerase (PCR) e a Reação em Cadeia da Polimerase de Transcrição Reversa (RT-PCR) devem ser usados para detectar DNA pró-viral inserido no genoma de animais negativos para antígeno. Hofmann-Lehmann et al. ${ }^{(20)}$ identificaram que $10,0 \%$ dos animais avaliados eram negativos para o antígeno p27, mas pró-vírus positivos quando o DNA viral foi investigado no sangue total desses gatos. Coelho et al. ${ }^{(11)}$ detectaram a presença de DNA pró-viral em 47,5\% das amostras testadas usando FIV ac/FeLV ag test kit em Belo Horizonte, Brasil. Portanto, é provável que a porcentagem de gatos positivos detectados em nosso estudo seja menor do que a porcentagem real de gatos infectados com FeLV em decorrência do teste utilizado.

A porcentagem de animais positivos neste estudo é consideravelmente superior àquela observada em estudos epidemiológicos realizados nos Estados Unidos, 2,3\% ${ }^{(12)}$ e Canadá, 4,3\%(21); além de estudos 
realizados na Itália, Alemanha e Reino Unido com taxas de infecção de 3,0\%( ${ }^{(5)}, 3,8 \% \%^{(4)}$ e 5,0\%(17), respectivamente. Isso pode ser explicado pelo grande esforço no controle e erradicação da doença nesses países, com investimentos em programas de vacinação e diagnóstico dos animais ${ }^{(14,20)}$.

A associação encontrada, em que animais não esterilizados apresentaram menor chance de infecção por FeLV $(0,37$; IC95\%=0,16-0,86) quando comparados aos animais esterilizados, contraria os resultados observados por Almeida et al. ${ }^{(8)}$ e por Spada et al. ${ }^{(4)}$ que não observaram associação entre essas variáveis e também é diferente da verificada por Jorge et al.(7), que identificaram maiores chances de infecção por FeLV entre animais não esterilizados (6,18; IC95\%=3,27-12-23). Sabe-se que a transmissão de FeLV ocorre principalmente via contato prolongado com saliva e secreções nasais de gatos infectados, hábito de higienização entre animais, mordedura e compartilhamento frequente de fontes de água e comida de animais doentes com animais susceptíveis, e que a esterilização é uma forma de reduzir esse contato, pois modifica o comportamento reprodutivo e territorial dos animais ${ }^{(21,22)}$. No presente estudo, em função do delineamento caso-controle, não foi possível estabelecer com precisão a precedência da esterilização (fator de risco/proteção) em relação à infecção (desfecho), o que seria desejável para melhor explicar a direção da associação verificada entre as variáveis.

Com relação à variável idade, Knotec et al. ${ }^{(2)}$, Hagiwara et al. ${ }^{(6)}$, Jorge et al. ${ }^{(7)}$ e Almeida et al. ${ }^{(8)}$ também identificaram maior chance de infecção em animais com idade entre um e quatro anos; diferentemente de Hosie et al. ${ }^{(17)}$ que verificaram maior chance para animais com idade inferior a um ano. A literatura indica que os animais mais jovens são mais suscetíveis à infecção do que os animais mais velhos, devido à imaturidade do sistema imunológico ${ }^{(15)}$. Apesar disso, animais entre um e quatro anos de idade já atingiram a maturidade física e sexual e estão mais propensos a ter contato direto e frequente com outros animais, o que pode aumentar o risco de transmissão viral e a infecção pelo FeLV ${ }^{(6,7)}$.

Não foi identificada associação entre acesso à rua e infecção por FeLV, ao contrário do verificado por Little et. al. ${ }^{(19)}$, Jorge et. al. ${ }^{(7)}$ e Almeida et. al. ${ }^{(8)}$. Essa associação é bem conhecida e justificada pelo fato de que o acesso à rua permite maior contato entre animais de diferentes estados sanitários, sendo isso associado a maiores taxas de transmissão do vírus. Neste estudo, o resultado encontrado provavelmente pode ser explicado pela dificuldade em determinar os hábitos dos animais, levando a erros de classificação e, consequentemente, alterando os resultados das análises.

A ausência de associação entre a variável sexo (macho ou fêmea) e infecção por FeLV também foi observada em outros estudos ${ }^{(4,6,8,17)}$. A transmissão do FeLV se dá, principalmente, pelo contato direto com saliva e secreções nasais contaminadas. Portanto, as diferenças comportamentais entre machos e fêmeas, como o comportamento territorialista dos machos, aparentemente, não afetam a incidência da doença.

O prognóstico para gatos FeLV positivos persistentemente virêmicos é desfavorável e a maioria desenvolverá doenças relacionadas à infecção ${ }^{(14,22)}$. No presente estudo, a maior parte dos animais positivos $(79,4 \%)$ para FeLV manifestaram algum sinal clínico da doença, o que também foi relatado por Knotec et al. ${ }^{(2)}$. No presente estudo, 20,6\% dos animais FeLV positivos apresentavamse assintomáticos. Segundo Hofmann-Lehmann et al. ${ }^{(24)}$, alguns animais virêmicos podem se manter saudáveis por período de tempo prolongado antes de manifestar sinais clínicos da doença e, ainda, segundo Lutz et al. ${ }^{(14)}$ cerca de $30-40,0 \%$ dos gatos FeLV positivos apresentam viremia transitória.

A infecção por FeLV pode exibir ampla variedade de sinais clínicos ${ }^{(20)}$. A ocorrência de sinais inespecíficos foi semelhante à observada por Knotec et al. ${ }^{(2)}$, em que 59,4\% dos animais FeLV positivo apresentavam sintomatologia inespecífica. Sabendo que a FeLV pode levar ao desenvolvimento de diversas doenças como neoplasias, alterações hematológicas, neurológicas e gastrointestinais, espera-se 
que a maior parte dos animais FeLV positivos e sintomáticos apresente sinais clínicos inespecíficos como prostração, apatia, perda de peso e hiporexia. Reinacher ${ }^{(25)}$ encontrou linfadenomegalia periférica em $8,0 \%$ dos animais infectados por FeLV, percentual menor àquele identificado no presente estudo $(11,8 \%)$.

Aocorrência de sinais respiratórios nos animais positivos foi de 20,6\%. Outros estudos reportaram taxas variando de $10,0 \%$ a $43,8 \%{ }^{(2,25)}$. Os sinais clínicos podem ser explicados pela presença de neoplasias intratorácicas mediastinais, efusão pleural ou ainda pela associação com doenças inflamatórias como pneumonia e pleurisia, achados comuns em felinos apresentando infecção por FeLV. Doenças inflamatórias do trato respiratório como rinite, pneumonia e pleurite foram encontradas em 10,0\% de felinos apresentando infecção por FeLV ${ }^{(25)}$. No presente estudo, 23,5\% dos gatos positivos para FeLV foram diagnosticados com linfoma mediastinal, fato que justifica a sintomatologia respiratória encontrada.

As alterações relacionadas ao sistema digestório foram encontradas em 14,7\% dos animais positivos. Enterite associada ao FeLV foi relatada em 12,0\% dos animais FeLV positivos em estudo realizado por Reinacher ${ }^{(25)}$. Essa afecção é caracterizada por degeneração das células epiteliais e necrose das criptas intestinais ${ }^{(20)}$. Knotec et al. também descreveram sinais clínicos gastrointestinais em 54,2\% de animais FeLV positivos $^{(2)}$.

Os sinais neurológicos apresentados por dois animais, tetraparesia não ambulatória e paralisia, estiveram associados a lesões no sistema nervoso central. Carmichael et al. ${ }^{(26)}$ reportaram alterações neurológicas em animais FeLV positivos livres de alterações neoplásicas ou hematológicas, sugerindo associação entre infecção por FeLV e mielopatia degenerativa. Spodnick et al. ${ }^{(27)}$ avaliaram 21 gatos com linfoma espinhal e encontraram $84,2 \%$ de animais positivos para o FeLV. Reinacher ${ }^{(25)}$ encontrou $11,0 \%$ de animais FeLV positivos apresentando sinais neurológicos.

A associação observada entre a presença de neoplasias hematopoiéticas e infecção por FeLV já havia sido descrita em outros estudos, os quais relatam que gatos naturalmente infectados por FeLV apresentam maior risco de desenvolver linfoma ou leucemia do que gatos não infectados ${ }^{(28,29)}$. As neoplasias hematopoiéticas estiveram presentes em 29,4\% dos animais FeLV positivos, valor semelhante àquele encontrado por Reinacher ${ }^{(25)}$, em que 23,0\% dos felinos persistentemente virêmicos apresentavam linfoma ou leucemia. No presente estudo, todos os gatos com linfoma ou leucemia apresentavam-se infectados por FeLV, resultado semelhante àqueles obtidos por e Reinacher ${ }^{(25)}$, que encontrou 92,0\% de animais com neoplasias hematopoiéticas infectados por FeLV. Estudos mais recentes, entretanto, encontraram percentuais bem menores, variando de 20 a 30,0\%. A redução da prevalência de infecção por FeLV em gatos apresentando tumores hematopoiéticos, observada em países desenvolvidos, parece ser devido à diminuição da prevalência do vírus entre a população geral de gatos, uma vez que esses países investiram bastante no controle e erradicação da doença ${ }^{(13,14,20,36)}$.

Foi observada maior ocorrência de citopenias (anemia e leucopenia) em animais positivos para FeLV quando comparado àqueles negativos. Esse achado também foi evidenciado por Gleich e Hartmann ${ }^{(30)}$ em estudo no qual animais FeLV positivos apresentaram maior risco de desenvolver anemia e leucopenia quando comparados ao grupo controle. Outros estudos também relataram anemia e leucopenia como os principais achados hematológicos encontrados em animais FeLV positivos ${ }^{(17,18)}$. Entretanto, um estudo realizado por Spada et al. ${ }^{(4)}$ não identificou associação entre infecção por FeLV e alterações hematológicas. Anemia arregenerativa leve a moderada é um dos achados hematológicos mais comuns na infecção por $\mathrm{FeLV}^{(20,31)}$. Cerca de $90,0 \%$ das anemias associadas ao FeLV são arregenerativas, resultantes do efeito supressivo do vírus na medula óssea e pela infecção primária das células progenitoras hematopoiéticas ${ }^{(20)}$. A leucopenia está muitas vezes associada à neutropenia 
e linfopenia ${ }^{(32)}$, devido ao efeito citopático do vírus na linhagem neutrofílica, à redução de linfócitos $\mathrm{CD} 4+\mathrm{e}$, principalmente, $\mathrm{CD} 8+$ ou devido à síndrome semelhante à panleucopenia caracterizada por severa leucopenia ${ }^{(33)}$. Esse último achado foi reportado em 9,0\% de animais infectados por FeLV ${ }^{(25)}$.

A associação entre hiperproteinemia e infecção por FeLV pode ser explicada pelo aumento de gama globulinas e das $\alpha 1$ e $\alpha 2$ globulinas, que são proteínas de fase aguda, consideradas marcadores de doenças inflamatórias, neoplásicas ou infecciosas, comumente encontradas em animais infectados por $\mathrm{FeLV}^{(34)}$.

No presente estudo, não foi identificada associação entre azotemia ou aumento de enzimas hepáticas e infecção por FeLV. Resultados semelhantes ao encontrado por Gleich e Hartmann ${ }^{(30)}$, embora fosse possível tal associação devido às diferentes lesões causadas pelo vírus no organismo do animal.

\section{Conclusões}

De acordo com a metodologia utilizada e a amostra obtida nesta pesquisa, é possível concluir que idade, anemia, leucopenia, neoplasia hematopoiética e hiperproteinemia foram associadas à infecção pelo FeLV. A faixa etária de 1 a 4 anos apresentou maior chance de infecção. Sexo e acesso à rua não foram associados à infecção pelo FeLV.

A apresentação clínica de gatos positivos para o FeLV é ampla, com possível envolvimento dos sistemas hematopoético, respiratório, digestivo, dermatológico e neurológico, o que demonstra a importância de se colocar o FeLV como um diagnóstico diferencial importante para gatos domésticos, independentemente do sinal clínico apresentado.

A limitação do nosso estudo foi o uso de um teste que não detecta infecções regressivas. Apesar disso, encontramos alta prevalência de infecção por FeLV, indicando a necessidade de ações que previnam essa doença infecciosa na região estudada.

\section{Referências}

1. Malik R, Kendall K, Cridland J, Coulston S, Stuart AJ, Snow D, et al. Prevalences of feline leukemia virus and feline immunodeficiency virus infection in cats in Sydney. Aust Vet J. 1997; 75(5):323-7.

2. Knotec Z, Hájková P, Svoboda M, Toman M, Raska V. Epidemiology of feline leukemia and feline immunodeficiency virus infections in the Czech Republic. J Vet Med. 1999;46: 665-71.

3. Yilmaz H, Ilgaz A. Prevalence of FIV and FeLV infections in cats in Istambul. J Feline Med Surg. 2000; 2: 69-70.

4. Spada E, Proverbio D, Pepa A, Perego R, Baggiani L, DeGiordi GB, et al. Seroprevalence of feline immunodeficiency virus, feline leukemia virus and Toxoplasma gondii in stray cat colonies in northern Italy and correlation with clinical and laboratory data. J Feline Med Surg. 2012;14:369-77.

5. Englert T, Lutz H, Sauter-Louis C, Hartmann K. Survey of the feline leukemia virus infection status of cats in Southern Germany. J Feline Med Surg. 2012;14:392-98.

6. Hagiwara MK, Jorge JJ, Stricagnolo C. Infecção pelo vírus da leucemia felina em gatos de diversas cidades do Brasil. Rev Clin Vet. 2007;66:44-50. Brazil. 
7. Jorge JJ, Ferreira F, Hagiwara MK. Risk factors for feline leukemia vírus (FeLV) infection in cats in São Paulo, Brazil. Braz J Vet Res An Sci. 2011;48(5):392-98.

8. Almeida NR, Danelli MGM, Silva LHP, Hagiwara MK, Mazur C. Prevalence of feline leukemia virus infection in domestic cats in Rio de Janeiro. J Feline Med Surg. 2012;14:583-86.

9. Medeiros SO, Silva BJA, Carneiro AL, Ferreira Júnior OC, Tanuri A. Evaluation of two point-of-care tests to diagnosis of FIV and FeLV infections. Arq Bras Med Vet Zootec. 2019;71:447-45.

10. Teixeira BM, Rajão DS, Haddad JPA, Leite RC, Reis JKP. Ocorrência do vírus da imunodeficiência felina e do vírus da leucemia felina em gatos domésticos mantidos em abrigos no município de Belo Horizonte. Arq Bras Med Vet Zootec. 2007;59(4):939-42. Brazil.

11. Coelho FM, Maia MQ, Luppi MM, Costa EA, Luiz APMF, Ribeiro NA, Bomfim MRQ, Fonseca FG, Resende M. Occurrence of feline leukemia virus in Felis cattus in Belo Horizonte. Arq Bras Med Vet Zootec. 2011;63:778-83.

12. Levy JK, Scott HM, Lachtara JL, Crawford PC. Seroprevalence of feline leukemia virus and feline immunodeficiency virus infection among cats in North America and risk factors for seropositivity. J Am Vet Med Assoc. 2006;228(3):371-76.

13. Gabor LJ, Jackson ML, Trask B, Malik R, Canfield PJ. Feline leukaemia virus status of Australian cats with lymphosarcoma. Aust Vet J. 2006;79(7):476-81.

14. Lutz H, Addie D, Belák S, Boucraut-Baralon C, Egberink H, Frymus T et al. Feline leukaemia. ABCD guidelines on prevention and management. J Feline Med Surg. 2009;11(7):565-74.

15. Hartmann K. Clinical aspects of feline retroviruses: A review. Viruses. 2012;4:2684-710.

16. Stutzer B, Muller F, Majzoub M, Lutz H, Greene CE, Hermanns W, et al. Role of latent feline leukemia virus infection in nonregenerative cytopenias of cats. J Vet Int Med. 2010;24:192-7.

17. Hosie MJ, Robertson C, Jarrett O. Prevalence of feline leukaemia virus and antibodies to feline immunodeficiency virus in cats in the United Kingdom. Vet Rec. 1989;125:293-7.

18. Arjona A, Escolar E, Soto I, Barquero N, Marin D, Gomez-Lucia E. Seroepidemiological survey of infection by feline leukemia virus and immunodeficiency virus in Madrid and correlation with some clinical aspects. J Clin Microbiol. 2000;38(9):3448-9.

19. Hartmann K. Feline leukemia virus infection. In: Greene CE, editor. Infectious diseases of the dog and cat. Saint Louis: Elsevier Sauders; 2006. p.105-131.

20. Hofmanm-Lehmann R, Huder JB, Gruber S, Boretti F, Sigrist B, Lutz H. Feline leukaemia provirus load during the course of experimental infection and in naturally infected cats. J Gen Virol. 2001;82:1589-96.

21. Little S, Sears W, Lachtara J, Bienzle D. Seroprevalence of feline leukemia virus and feline immunodeficiency virus infection among cats in Canada. Can Vet J. 2009;50:644-8.

22. Hardy Jr WD, Hess PW, MacEwen EG, McClelland AJ, Zuckerman EE, Essex M, et al. Biology of feline leukemia virus in the natural environment. Cancer Res. 1976;36:582-88.

23. Pacitti AM, Jarrett O, Hay D. Transmission of feline leukaemia virus in the milk of a non-viraemic cat. Vet Rec. 1986;118:381-4.

24. Hofmann-Lehmann R, Holznagel E, Aubert A, Ossent P, Reinacher M, Lutz H. Recombiant FeLV vaccine: long term protection and effect on course and outcome of FIV infection. Vet Immunol Immunopathol.

Cienc. anim. bras., Goiânia, v.20, 1-10, e-50797, 2019 
1995;46:127-37.

25. Reinacher M. Diseases associated with spontaneous feline leukemia virus (FeLV) infection in cats. Vet Immunol Immunopathol. 1989;21:85-95.

26. Carmichael KP, Bienzle D, McDonnell JJ. Feline leukemia virus-associated myelopathy in cats. Vet Pathol. 2002;39:536-45.

27. Spodnick GJ, Berg J, Moore MF, Cotter SM. Spinal lymphoma in cats: 21 cases (1976-1989). J Am Vet Med Assoc. 1992;200(3):373-6.

28. Cotter SM, Hardy Jr WD, Essex M. Association of feline leukemia virus with lymphosarcoma and other disorders in the cat. J Am Vet Med Assoc. 1975;166(5):449-54.

29. Stutzer B, Simon K, Lutz H, Majzoub M, Hermanns W, Hirschberger J, et al. Incidence of persistent viraemia and latent feline leukemia virus infection in cats with lymphoma. J Feline Med Surg. 2011;13:81-7.

30. Gleich S, Hartmann K. Hematology and serum biochemistry of feline immunodeficiency virus-infected and feline leukemia virus-infected cats. J Vet Int Med. 2009;23:552-8.

31. Shelton GH, Linenberger ML. Hematologic abnormalities associated with retroviral infections in the cat. Semin Vet Med Surg. 1995;10:220-33.

32. Brown MR, Rogers KS. Neutropenia in dogs and cats: a retrospective study of 261 cases. J Am Hosp Assoc. 2001;37:131-9.

33. Ogilvie GK, Tompkins MB, Tompkins WAF. Clinical and immunologic aspects of FeLV-induced immunosuppression. Vet Microbiol. 1988;17(3):287-96.

34. Miró G, Doménech A, Escolar E, Collado VM, Tejerizo G, De Las Heras A. Plasma electrophoretogram in feline immunodeficiency virus (FIV) and/or feline leukaemia virus (FeLV) infections. J Vet Med A Physiol Pathol Clin Med. 2007;54:203-9. 